\title{
The Problems of Transitivity Studies and Its Solution
}

\author{
Huijing Wang \\ College of International Studies, Southwest University, Chongqing, China \\ Email: xiaowangjing26@sina.com
}

Received 29 September 2015; accepted 23 October 2015; published 27 October 2015

Copyright (C) 2015 by author and Scientific Research Publishing Inc.

This work is licensed under the Creative Commons Attribution International License (CC BY). http://creativecommons.org/licenses/by/4.0/

(c) (i) Open Access

\begin{abstract}
Transitivity is an important grammatical issue and has been a hot topic in linguistic theories. It has been studied from different approaches. This paper aims to describe the main features and propositions about transitivity in the view of different theories. After pointing out the unsolved problems of traditional and typological views, the paper believes that cognitive approach to transitivity is promising.
\end{abstract}

Keywords

Transitivity, Typological View, Cognitive Approach

\section{Introduction}

Transitivity has been a hot topic in linguistic studies for a long time. It has been studied from different angles. It is not as straightforward as the traditional grammar's view. Traditionally, it is a verb distinctive feature and related with the verb taking direct object. But this clear-cut dichotomy of transitivity cannot explain many linguistic facts. The functional view of Halliday [1] [2] regards it as an important part of ideational system and is a semantic notion which is quite different from what we focus on in the paper. The typological study of transitivity is a great turning point, viewing transitivity as a continuum. However, the semantic features listed lack the conceptual correlation. The cognitive approach uses the cognitive model to seek the semantic basis of transitivity, which has more explanatory power. The significance of this study is to find out the problems of traditional approaches and have a clearer picture of the features of transitivity in the frame of cognitive linguistics.

\section{Traditional Grammar's View of Transitivity}

Traditional grammar, in parallel with American Structural Grammar and Transformational-Generative Grammar, etc., refers to the traditional schoolroom grammar. It defines and classifies words into part-of-speech categories, 
one of which is the verb category. A verb is defined as a word or word group that expresses action, condition, or state of being [3]. Generally, there are three main full verb classes, namely, transitive verbs, intransitive verbs and copular (linking) verbs [4]. Of the three types of verbs, the former two are regarded as action verbs. Intransitive verbs refer to those which require no words to complete its meaning while transitive verbs are followed by one or more than one object or complement to complete its meaning [3]. For example:

(1) John grew.

(2) Rain falls often.

(3) Lily enjoys music.

(4) Bill washed the clothes.

The verbs grew and fall in sentences (1) and (2) are intransitive because no object is required to follow the verbs. According to Lyons (1968), they are one-place verbs and the one-place, in the two examples, is filled by John and rain separately. The verbs enjoy and gave are transitive verbs, followed by one or two objects. They are two-place verbs, one of the places being filled by the subject Lily and Bill, and the other by the object music and clothes. The term transitivity, derived from the division of transitive and intransitive verbs, concerns linguistic phenomena which have to do with transitive clauses, including their relationship to intransitive clauses [5]. There has been a long tradition of studying "transitivity", “transitive clauses" and "intransitive clauses". Traditionally, a clause that has both a subject and a direct object is said to be transitive. Transitivity is fairly defined as follows [6].

Transitive clauses contain an object. An activity or action "goes across" from the subject to the object. It is sometimes stated additionally that the object is affected by the activity, and that transitive clauses can be turned into passive clauses.

Intransitive clauses lack an object. No activity is transferred.

According to this definition, examples of transitive clauses include:

(5) Mr. Jones repaired cars.

(6) Bill killed his Aunt.

(7) I hit him.

(8) He wrote a good book.

(9) He grew roses in his garden.

Examples of intransitive clauses include:

(10) The flower grew.

(11) The problem remained.

(12) He sat down.

(13) Jim died yesterday.

A brief look at these examples may give an impression that the issue of transitivity is straightforward. The traditional definition assumes a clear-cut dichotomy between transitive and intransitive clauses. However, there are certain problems beyond traditional explanation. It is true that, in transitive clauses, the action is expressed by the verb "pass over" from the subject to the object. But I hear you is regarded as transitive, though in this case, the action, if any action is in fact referred to, is the other way round. Besides, the infelicity of the corresponding passives in some transitive clauses calls their transitivity into question. For example,

(14) That little boy resembles my nephew.

(15) They have many books.

(16) *My nephew is resembled by that little boy.

(17) * Many books are had by them.

In contrast, some traditionally defined intransitive clauses have their corresponding passives, for instance, Jerry bumped into John. By traditional definition, this is an intransitive clause. However, its passive form is acceptable and we have John was bumped into by Jerry. From the above further examples, we come to realize that transitivity is more subtle and complex than the traditional definition has proposed. Similar cases can also be found in Chinese.

(18) 15 万就可以买一辆二手车。

150 thousand can buy a second-hand car.

(19) *一辆二手车可以被 15 万买。

A second-hand car can be bought by 150 thousand.

(20) 死了一个孩子。 
Died a child.

(21) *一个孩子被死了。

A child was died.

(22) 他像我弟弟。

He looks like my brother.

(23) 我听你唱歌。

I hear you sing a song.

The Chinese instances such as (18) and (20) are obviously regarded as transitive clauses, but their corresponding passives (19) and (21) are clearly infelicitous. Instances (22) and (23) question another property in the traditional definition - the action goes across from the subject to the object and sometimes the object is affected by the action. In both of the two instances, we cannot clearly see the going-across process of any action or activity. If there is any, in sentence (23), the action passes over reversely from the object to the subject.

Obviously up till now, transitivity is seen to be far more complex than the matter of the occurrence of a nominal in direct-object position, passivizability, or the passing over of action. This traditional clear-cut definition of transitivity leaves some difficult problems unsolved and fails to provide a clear picture of transitivity itself. Thus it is necessary to renew it from other promising perspectives.

\section{Halliday's Model of Transitivity}

Halliday's study on transitivity from the functional approach is so well-known as not to be avoided in this paper. Systemic-functional linguistics, represented by Halliday, is a theory centering round the notion of language function. It is functional in the sense that it places the function of language as central, and is designed to account for what language does and how it does. In its conceptual framework, "language is interpreted as a system of meanings, accompanied by forms through which the meaning can be realized" [2]. How do human beings make sense of what goes round them and inside them? How do human beings come to a clear mental picture of reality? In systemic-functional framework, language is the product of social activities. As a means for interpersonal communication, it takes on functions of various kinds. Halliday [1] [2] views language in terms of three metafunctions, namely, ideational, interpersonal and textual function. It is the ideational function of language that enables human beings to express a variety of experiences, both external and internal. That is to say, it serves as a way of representing patterns of experiences. To achieve this goal, clause plays a central role in that it embodies a general principle that reality is made up of PROCESSES, by which people model experience. It is clear that our experience "consists of 'going-on'-happening, doing, sensing, meaning, and being and becoming. As well as being a mode of action, of giving and demanding goods- $\&$-services and information, the clause is a mode of reflection, of imposing order on the endless variation and flow of events. The grammatical system by which this is achieved is TRANSITIVITY" [2]. People construe the complex world on the basis of transitivity system which helps to sort out experiences and divide them into a manageable set of PROCESS TYPES. The semantic processes expressed by clauses have three components:

(1) Process itself, which will be expressed by the verb phrase in a clause.

(2) The participants involved in the process. These roles are typically relied by noun phrases in the clause.

(3) The circumstances associated with the process, normally expressed by adverbial and prepositional phrases.

Transitivity is a semantic system specifying different types of processes which form separate semantic categories on the basis of which experience is reflected in language. Transitivity is regarded as a system construing the world of experience into limited number of processes, ranging from material, mental, relational, behavioral, verbal to existential, the first three of which are principal "in that they are the cornerstones of the grammar in its guise as a theory of experience" [2]. The material processes are those involving physical actions, such as running, throwing and cooking. It is the process of "doing" with two inherent participant roles, the Actor and the Goal. The former role, animate or inanimate, is an obligatory element which represents the "doer" of the process expressed by the clause. The latter represents the person or entity affected by the process. The mental process accounts for processes of sensing, which can be subdivided into perception processes (seeing, hearing), reaction processes (liking, hearing) and the cognition of cognition (thinking, understanding). The participants related to the process are the Sensor, the conscious being, and Phenomenon, being that which is perceived, reacted or thought about. The relational process expresses processes of being which may be attributive or identifying. The participants in the first subdivision are the Carrier, which "carries" the attribute; and the other is Attribute. As 
the function of the second type is to identify one entity in terms of another, the participants are therefore the Identified and Identifier. Other processes are located at the boundaries of the principal processes.

All in all, the term transitivity in Halliday's systematic-functional theory refers to "a system for describing the whole clause, rather than just the verb and the object". Take the material process as an example, there are cases in which the Goal is absent. For example, He ran away. This clause has the Actor only, lack of object after the verb, so traditionally it is regarded as intransitive clause. Transitivity in Halliday's view is therefore being used in a much broader sense. It is more like a superordinate, including both transitivity and intransitivity. There is consequently no such division between transitive verbs and intransitive verbs as in traditional grammar. So transitivity in Halliday's work is different from that in our present paper. We use transitivity here in its narrow sense related to transitive and intransitive clauses. On the other hand, Halliday's idea shares similarity with the main claims in cognitive grammar in that they both put emphasis on daily experience of human beings and semantic meaning. However, in his framework, all the processes are considered equal in status. Furthermore, it is not quite possible to solve the remained problems in traditional grammar.

\section{Hopper and Thompson's Model of Transitivity}

Hopper and Thompson [7] have shown that the phenomenon of transitivity is intimately connected with the complex of semantic and morphosyntactic parameters. It involves a number of components, only one of which is the presence of an object of the verb. They suggest a list of transitivity parameters as follows [7].

\begin{tabular}{lll}
\hline Components of transitivity & high & low \\
participant & two or more participants & One participant \\
kinesis & action & non-action \\
aspect & telic & atelic \\
punctuality & punctual & non-punctual \\
volitionality & volitional & non-volitional \\
affirmative & affirmative & negative \\
mode & realis & irrealis \\
agency & a high in potency & a low in potency \\
affectedness of object & object totally affected & object not affected \\
individualization of object & object highly individualized & object non-individualized \\
\hline
\end{tabular}

They point out that generally speaking a clause which has one of the above semantic features will be morphosyntactically more like a typical transitive clause than another identical clause which lacks that feature. According to their list, "the canonical transitive clause has two participants, reports a kinetic event, is punctual and perfective, has a definite referential, individuated, and wholly affected patient and a volitional agent which ranks high on the animacy hierarchy, and is affirmative and realis [8]”. For example,

(24) John likes roses.

(25) He beat his son.

(26) 老李走了。

Lao Li left.

(27) 老李喜欢香烟。

Lao Li likes cigarette.

(24) is more like a prototypical transitive clause or it is higher in transitivity than (25) due to the fact that the former possesses some properties which the latter lacks. To put things more clearly, (24) is punctual and perfective and has an individuated and totally affected patient. (26) is kinetic, perfective, punctual and has a volitional agent while (27) has only one property-has two participants. Therefore, (26) is more approximate to a canonical clause than (27) is. We take their criteria as insufficient in that semantic parameters clearly are only a part of them. Other factors may be involved in such as syntactic properties. To Hopper and Thompson, transitivity, as 
defined by these parameters, shows a high degree of correlation with foregrounded information. To be slightly different, transitivity complex is believed to exist in order to function as a means of coding foregrounded information in discourse. So they put much emphasis on discourse rather than transitivity itself. In some way, their study is typological because they subdivide transitive verbs and intransitive verbs into four categories: transitive verbs showing high level of transitivity, transitive verbs showing low level of transitivity, intransitive verbs showing high level of transitivity, and intransitive verbs showing low transitivity. Though we do not see much significance of that subdivision of verbs, we find their list of semantic properties inspiring.

\section{Cognitive Grammar's View of Transitivity}

Within the framework of Cognitive grammar, a central claim is that the grammatical units are symbolic in nature and all the valid grammatical constructs have conceptual basis. More precisely, the meaning of linguistic expression is a cognitive structure characterized with reference to cognitive domain, where "a domain can be any sort of conceptualization: a perceptual experience, a concept, a conceptual complex, an elaborate knowledge system, etc. [9]", most of which are idealized cognitive models in the sense of Lakoff [10]. They are fundamental to our experience and part of human beings' general conceptual apparatus. A clause in his term profiles the interaction between agent and patient and their relationship is construed as an event. Cognitive models of events, reflecting people's everyday experience, offer the basis of the typical clause structures. Langacker (2004) proposes that the canonical event model, from the combination of three cognitive models underlies the organization of a prototypical finite transitive clause. To start with, people tend to conceive the world as being populated by discrete objects, some of which are capable of moving round and interacting with others, particularly through direct physical contact. The motion is driven by energy, some of which is supplied internally while some is from outside source. A useful cognitive model called billiard-ball or action chain is useful in describing a prototypical finite clause. "An action chain arises when one object makes forceful contact with another, resulting in a transfer of energy; this second object is thereby driven into contact with a third, again resulting in the transmission of energy; and so on indefinitely, until the energy is exhausted or no further contact is made [9]". Another cognitive model relative to the conception of experience is termed stage model. Since in many respects people's role as observers is analogous to that of someone watching a play, an observer is capable of focusing his attention on a limited portion of the world round him at any one time. The viewers are likely to organize the scenes they observe in terms of distinct participants who interact within an inclusive and reasonably stable setting. According to Langacker, this model idealizes an essential aspect of the ongoing experience: the observation of sequences of external events, each involving the interactions of participants within setting. Additionally, from the countless instances of experience, people develop a conception of certain typical roles-role archetypes that participants play in event. Such archetypes presumably function as the fundamental based on which people organize their conception of event. As Langacker puts it, the archetypal agent role is that of a person who volitionally carries out physical activity resulting in contact with some external object and the transmission of energy to that object. The archetypal patient, its polar opposite, is an inanimate object that absorbs the energy transmitted by externally physical contact and thereby undergoes some change of state. Moreover, the instrument role is an inanimate object through which an agent affects the patient. The experiencer role is taken by a person engaged in mental activity, while a mover changes position related to its surrounding. He also highlights that these roles are grounded in daily experience with its non-linguistic origin. With the contributions of these foregoing models, Langacker puts forward the canonical event model representing normal observation of prototypical action sketched in Figure 1.

A viewer (V) observes an event from a vantage point external to its setting. The event consists of two participants of an agent and a patient represented by the two circles respectively. The transmission of energy is depicted by a double arrow whose direction clearly shows the energy transferred from agent to patient. The squiggly arrow indicates the internal change of the patient as a result of the energy transmission. When people are in the process of coding the event by using linguistic expressions, they show the corresponding relationship between the cognitive model and the structures of clauses. For instance, the speaker and addressee correspond to the viewer, the verbs to the energetic interaction, other grammatical elements to participants or setting. Langacker claims that the canonical event model reflects the prototypical value of a finite transitive clause in that it conceptually correspond to the archetype of an energetic interaction and structurally manifests the fullest array of properties that are specifically clausal. As a notion for the characterization of the finite clause prototypes, 


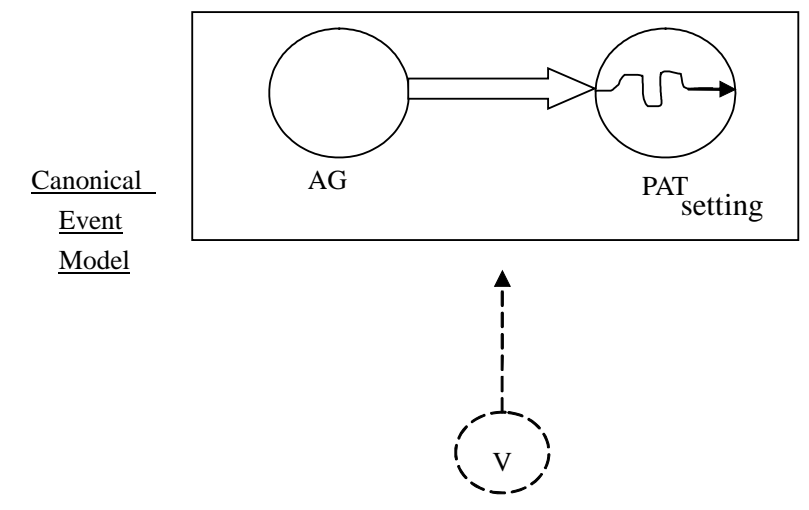

Figure 1. Canonical event model.

transitivity is seen not in terms of nominal occurring in a particular structure configuration, rather a matter of degree. In line with Hopper and Thompson (1980)'s work on the proprieties with reference to transitivity, Langacker believes that all those conceptual factors can be identified as facets of the canonical event model which tie them together and provide a basis for the prototypical notion of transitivity. For example, Jack broke my glass. The organization of this sentence reflects the canonical event model and it is quite high in transitivity because it corresponds to the prototype regarding multiple factors of the model. However, transitivity itself is not his main concern, so Langacker himself has not made any elaborate prototypical study on it. Then what makes Langacker's contribution greatly worth mentioning here is that his canonical event model provides a semantic basis for transitivity and connection between semantic meaning and syntactic forms of transitive clauses, which is basic for the following exploring of prototype effects in transitivity.

\section{Conclusion}

In traditional grammar's view, transitivity is a verbal phenomenon that is not related with the meaning of the whole sentence. The traditional definition of transitivity cannot solve many problems. For example, some clauses with verbs followed by direct objects do not have their passive counterparts. Additionally, some clauses are still considered transitive though there is no perceptible affection imposed on the objects. Typological studies regard transitivity as a continuum and list a series of semantic and syntactic features as criteria to judge the different degree of transitivity. But it is also problematic when the features are applied due to the reason that it mixes the semantic and syntactic features together. Cognitive approaches not only describe the inherent features of transitivity but also explain the cognitive ability of human beings behind the language form itself. Thus, it will surely have a stronger explanatory power than any other approaches mentioned above. In the future, the cognitive approach's research will be complemented by experimental studies [11].

\section{Funding}

This article is supported by the Southwest University "Fundamental Research Funds for the Central Universities" No: SWU0909651.

\section{References}

[1] Halliday, M.A.K. (1970) Language Structure and Language Function. In Lyons, J., Ed., New Horizons in Linguistics, Penguin, Harmondsworth, 140-165.

[2] Halliday, M.A.K. (2000) An Introduction to Functional Grammar. Foreign Language Teaching and Research Press,. Beijing.

[3] LaPalombara, L.E. (1976) An Introduction to Grammar. Winthrop Publishers, Cambridge.

[4] Quirk, R., Greenbaum, S., Leech, G. and Svartvik, J. (1985) A Grammar of Contemporary English. Longman, New York.

[5] Tsunoda, T. (1999) Transitivity. In Brown, K. and Miller, J., Eds., Concise Encyclopedia of Grammatical Categories, John Benjamins, Elsevier, 383-391. 
[6] Hartman, R.R.K. and Stork, F.C. (1972) Dictionary of Language and Linguistics. Applied Science Publishers, Essex.

[7] Hopper, P. and Thompson, S.A. (1980) Transitivity in Grammar and Discourse. Language, 56, 251-299. http://dx.doi.org/10.1353/lan.1980.0017

[8] Delancy, S. (1987) Transitivity in Grammar and Cognition. In Tomlin, R.S., Ed., Coherence and Grounding, John Benjamins, Amsterdam/Philadelphia. http://dx.doi.org/10.1075/tsl.11.04del

[9] Langacker, R.W. (2004) Foundations of Cognitive Grammar, II. Stanford University Press, Stanford.

[10] Lakeoff. (1987) Women, Fire, and Dangerous Things. The University of Chicago Press, Chicago.

[11] Theakston, A.L., Maslen, R., Lieven, E.V.M. and Tomasello, M. (2012) The Acquisition of the Active Transitive Construction in English: A Detailed Case Study. Cognitive Linguistics, 23, 91-129. 